\title{
Scientific publication during the pandemic
}

In December 2019, the world was impacted by the COVID-19 pandemic; nowadays, we may state that no section of society emerged unscathed from such disaster.

It is striking that the scientific world, involved in human drama and occupational burnout, experienced an amazing time. Never before so many answers have been requested or so many advances have been made in such a short period. ${ }^{1}$

However, such whirlwind of knowledge development evidenced the weaknesses and strengths of our scientific communication system.

During the pandemic, it was remarkable to see how the communication of scientific findings changed. Usually, scientific dissemination in mass communication media is necessary to reach the general audience. Such practice has increased significantly since the beginning of the millennium and is usually based on certain rules to maintain information integrity. ${ }^{2}$ Among such rules, it is stated that any disseminated information should be validated in advance by the scientific community. The route to such outcome implies the publication of the full text in peer-reviewed journals. Following this process, during which specialists discuss the pros and cons of each finding, information reaches the audience through the press, in general, disseminated by experts on the topic. ${ }^{3}$

The pandemic changed the route, sometimes skipping the most important steps and many times presenting partial or raw data to the population, who is certainly not prepared to assess them in an adequate manner. Moreover, it was not strange to see investigators describing their interim results during a press conference before laypersons instead of in a scientific event surrounded by their peers.

Frequent explanations, apologies, and denials have confirmed that the traditional route is still the right one: scientific peers, following a careful assessment of all information (eventually including raw data) should validate each investigation. ${ }^{4,5}$

Another phenomenon about how the scientific community faced the challenge of presenting its results was the proliferation of preprints. Although they have been in the scene for quite some time, preprints were not massively applied in biomedical investigation until the onset of the pandemic.
Such form of publication allows the scientific community to have interim data available, thus facilitating discussion and streamlining the subsequent editorial process.

The advantage of preprints is that they may be made public in very short time (skipping the necessary times of the editorial process), allow access to the feedback of those who read the manuscript, and allow to submit to journals an article that could have been enriched with the opinions of the community and is already in a format compatible with the subsequent scientific publication.

Although it seems that preprints have reached the world of biomedical publications to stay, ${ }^{6}$ it is worth remembering that these presentations lack the weight of a publication made in a peerreviewed journal.

In addition, the scientific editorial world faced another problem: an enormous volume of material and the need to publish it as soon as possible while maintaining scientific rigor. ${ }^{7}$ The pandemic generated a huge number of scientific articles, from isolated case reports to the most expected randomized clinical trials in recent history. The relevance of the work and the urgency to publish are not usually friends of scientific rigor and the possibility of introducing errors has been important. At this point is where we find one of the least recognized scientific aspects of the pandemic. That is the huge, selfless, and anonymous effort made by the entire scientific community to disseminate information about this new disease in the fastest time and with the greatest rigor possible. Undoubtedly, the editorial teams of many scientific journals made a major effort; however, who probably deserve the greatest recognition are peer reviewers, who have provided their knowledge and constructive opinions as never before. Even amid the praises and criticisms of the peer review system, ${ }^{8}$ during the pandemic, it has exhibited its most altruistic side.

During such unique times, it has also shown other unknown and auspicious aspects. The globalization of COVID-19 allowed investigators from emerging countries to have access to top level journals more easily than usual.

At the same time, we are facing an example of what a total open-access world would be in terms of scientific publication, because almost every 
publisher has offered free access to the full text of articles related to the pandemic. ${ }^{9}$

We hope that, as we settle in this new postpandemic(?) scenario, we remember what we have learned from such special times, forgetting the pettiness and opportunism of some and retaking the selflessness, sacrifice, and eagerness with which humanity faced a common danger.

Fernando Ferrero

Editor-in-chief

Archivos Argentinos de Pediatría

http: / / dx.doi.org/10.5546/ aap.2021.eng.362

To cite: Ferrero F. Scientific publication during the pandemic. Arch Argent Pediatr 2021;119(6):362-363.

\section{REFERENCES}

1. Chen Q, Allot A, Lu Z. LitCovid: an open database of COVID-19literature.Nucleic AcidsRes.2021;49(D1):D1534-40.

2. GuentherL.Science Journalism. Oxford Research Encyclopedia of Communication. 2019. [Accessed on: August 31 ${ }^{\text {st }}, 2021$ ]. Available at: https://oxfordre.com/communication/ view / 10.1093/ acrefore/9780190228613.001.0001/ acrefore9780190228613-e-901

3. Makri A. What do journalists say about covering science during the COVID-19 pandemic? Nat Med. 2021;27(1):1720.

4. Yeo-Teh NSL, Tang BL. An alarming retraction rate for scientific publications on Coronavirus Disease 2019 (COVID-19). Account Res. 2021;28(1):47-53.

5. Retraction Watch. Retracted coronavirus (COVID-19) papers. [Accessed on: August 26 $6^{\text {th }}, 2021$ ]. Available at: https: / / retractionwatch.com/retracted-coronaviruscovid-19-papers /

6. Ørstavik RE. Preprints are here to stay. Tidsskr Nor Laegeforen. 2021;141(4):10.4045/tidsskr.21.0148. Published 2021 Mar 8.

7. Ese H. How a torrent of COVID science changed research publishing - in seven charts. Nature. 2020;588(7839):553.

8. Tennant JP, Ross-Hellauer T. The limitations to our understanding of peer review. Res Integr Peer Rev. 2020;5:6.

9. Tavernier W. COVID-19 demonstrates the value of open access. What happens next? Coll Res Libr News. 2020;81(5):226. 